\title{
Correction to: Models of displacement and blocking force of ionic-polymer metal composites based on actuation mechanism
}

\author{
Liang Yang $^{1} \cdot$ Dongsheng Zhang ${ }^{1} \cdot$ Xining Zhang $^{1} \cdot$ Aifen Tian $^{2} \cdot$ Xixi Wang $^{2}$
}

Published online: 29 September 2020

c) Springer-Verlag GmbH Germany, part of Springer Nature 2020

Correction to: Applied Physics A (2020) 126:365 https://doi.org/10.1007/s00339-020-03546-x

In the original publication of the article, the fourth author's name was incorrect. The correct name is Aifen Tian, not Aifei Tian.
Publisher's Note Springer Nature remains neutral with regard to jurisdictional claims in published maps and institutional affiliations.

The original article can be found online at https://doi.org/10.1007/ s00339-020-03546-x.

Liang Yang

yangliang20070126@163.com

$\triangle$ Dongsheng Zhang

zds@xjtu.edu.cn

1 School of Mechanical Engineering, Xi' an Jiaotong University, Xi' an 710049, China

2 School of Materials Science and Engineering, Xi'an University of Science and Technology, Xi' an 710054, China 